\title{
MITURILE, CULTELE MISTERICE, FILOSOFIA GRECIEI ANTICE, FRONT COMUN PENTRU CONSTRUIREA ARTEI DE A EDUCA
}

\author{
Gabriela-Fulvia HOROBET ${ }^{*}$
}

\begin{abstract}
The Greek myth, the divine Greek mystical rituals and Greek Philosophy, common front for building the art of educating ${ }^{1}$. Originality, dynamism and elitism are the features that characterize the ancient Greece. Even the political and administrative domains point to this competitive characteristic aimed at overcoming challenges that will generate the best opportunities and solutions for Greece to achieve its most potential in those times. Thus, Greece evolves as a federation of states always racing to be the best at everything be it cultural, political, philosophical, scientific, economic, sports domains in order to ensure their country's prestige. The religious dimension had a huge influence on Education that was cherished by the ancient Greeks. Myth and artistic instruction mutually influenced themselves, moreover, he training bettered, ennobled the mythological heroes and heroines humanizing them. Athenian education was the standard training model in all Greece and aimed at a noble life that of aristocrats who could permanently relate to the mythological high standards of legendary Gods found in the pre-classic age. In Greek society Education for men mainly targeted virility mixed with wisdom inspired by Homer's ideal masculine type of hero who fitted the profile. The feminine archetype in the noble courts was essentially characterized by refined beauty due to the cultural model of distinguished manners, gentleness, sensitivity based on the chivalrous ideal woman always promoted in those times and the middle ages. The ideal lady had delicate features, exquisite
\end{abstract}

“PhD Student, Faculty of Orthodox Teology „Justinian Patriarch”, at University of Bucharest, Bucharest, Romania.

${ }^{1}$ Realizat sub îndrumarea Pr. Conf. Univ. Dr. Radu Petre Mureşan, care şi-a exprimat acordul pentru publicare. 
manners and character, beauty, charm was able to guide, tame and model the brutal warrior-like society. Moreover, maternity was the distinct feature of a woman beside her social status and functions, she was respected and praised since her presence made the world better, more beautiful, colourful and valuable filled with the purpose and motivation to live, fight and love. Pythagoras's mystery cult had many followers who set up the first school in the modern sense of the word that will serve as a model to all the great philosophers of the time who created their pedagogical theories and found schools: Aristotle's High school, Plato's Academy, Epicurus's school house. The classical age, the $5^{\text {th }}$ century created the greatest innovation of the civil organization: "the polis". Man is the human being whose natural environment is the city and humanity is the status of being a citizen". This is the real, responsible man, who has both civil and human rights and responsibilities. This is the real MAN, the concept of man officially forged, the responsible citizen. The mundane world needed to worship fortress' qualities. Platon convicted the artists and poets that wrote about annoying conjectural situations and everything else related to own feelings that were against the laws at that time. The laws needed to be applied through conviction or constraint if necessary. The overall human picture was dominated by universal ideas and patterns. We could actually say that thy were watching to keep the world's wreath of wonders safe. In the late $5^{\text {th }}$ century sophists pedagogy entered the scene, which raised the learning standards even higher. They build schools, organize the first conferences and also use antilogy.

Keywords: athenian education, Homeric hero, harmony unit, typical values, Ideas.

\section{Introducere}

În lucrarea de faţă, vom demonstra faptul că Paideia sau arta de a educa reprezintă izvorul permanent reîmprospătat al întregii dinamici care definește viața socială și nivelul de dezvoltare a societăţilor Greciei Antice, considerată, în mod total îndreptățit, leagănul civilizației europene. Eroii aveau forța mobilizatoare și modelatoare care a impregnat și influențat pedagogia tuturor perioadelor istorice următoare. Eroul era în legătură durabilă cu sacrul, revelat prin panteon, culte misterice și miturile aferente acestora. 
Armonia este starea de spirit ideală în care omul își poate desfășura la parametri optimi întreaga sa activitate creatoare sau de cunoaștere, de manifestare a propriei personalități statornicită în bucuria care se îmbină cu frumosul din care face parte ontic.

Un citat concentrează prezentarea idealului educațional în Grecia Antică: „Creează-te pe tine însuți, astfel încât în toate acțiunile tale, în toate împrejurările variate ale experienței tale să fii o unitate armonioasă, dreaptă, frumoasă și adevărată față de tine însuți”. Acest citat face parte din Tratatul despre sublim, lucrare de o inefabilă valoare literară a autorului grec anonim, iar acest enunț conține un adevăr imuabil care străbate și leagă, asemenea unui fir roșu, educația din toate timpurile.

Trei idei cheie sunt conţinute în acest extras literar:

1. „Creează-te pe tine însuți”, cu referire clară la construcția personală continuă în intervalul temporal 12-60 de ani, adică acea construcție trainică neîntrerupt consolidată și îmbogățită, capabilă să acopere atât vremelnica existență, cât și pe cea veșnică. Grecii antici considerau că educația de bază, sămânța educației morale, are nevoie de rădăcini puternice caracteriale, iar această importantă lucrare se realizează până la vârsta de 12-14 ani. Dacă temelia construcției este sănătoasă și foarte corect instalată, atunci omul va putea rezista la orice încercare și va putea performa la un nivel cât mai ridicat. $\mathrm{O}$ îndrumare pe potrivă în primii ani va conduce la autoeducație de calitate, la selecție a învățăturilor care să fie ilustrate în comportament pe măsura celor mai înalte așteptări. Modelarea performantă din primii ani ai vieții va fi continuată de automodelarea continuă.

2. Acțiunile, împrejurările și experiențele personale, suma tuturor acestor oportunități definesc o persoană, un caracter. De fapt, nu acestea în sinea lor, ci felul în care treci prin ele, maniera ta de a selecta și de a te raporta la actorii acestora, la toate elementele care compun aceste oportunități, felul în care se afirmă personalitatea omului în diverse situații de viață. $\mathrm{Cu}$ alte cuvinte, este vorba despre stilul personal de a acționa, de a se raporta la lume și viață, de a răspunde la provocările vieții.

3. ,Unitate armonioasă, dreaptă, frumoasă și adevărată față de tine însuți”, reprezintă produsul final al lucrării educaționale. Cea mai bună versiune personală se obține abia la final, după ce parcurgem fiecare perioadă și fiind mereu deschiși să învățăm. Învățarea se bazează pe 
antrenament continuu. Persoana umană se formează pe trei componente care o alcătuiesc: fizică, intelectuală/rațională şi spirituală/sufletească. În educația de mare valoare a fiecărei componente trebuie investit cu mare grijă și consideraţie încă de la început pentru ca sufletul să dispună de bucurie și de iubirea înălțătoare și aptă de a oferi continuitatea persoanelor care îi vor succeda.

Concluzia: Construiește-te pe tine, până ajungi la varianta ta ideală!

\section{Arta educaţiei în Grecia Antică}

Învățarea continuă este esențială în concepția vechilor greci. Ea este luptă continuă cu tine însuți, zbatere constructivă, zbucium pozitiv, acțiune, dinamism faptic și aspirațional. Se știe că, pentru vremea aceea, Grecia avea atât un statut politic, cât şi o compoziţie administrativă originală: federație de polisuri între care era o permanentă concurență, astfel încât să permită afirmarea diferențiată care să conveargă la sporirea prestigiului statului grec.

Omul grec era un specimen uman de elită, datorită faptului că era deschizător de numeroase căi ale cunoașterii care înnobilează. Iar una dintre marile direcții era aceea a Paideii, educația permanentă care realizează conexiunea cu lumea zeilor.

Se poate observa lesne că dimensiunea religioasă a avut o înrâurire esențială asupra educației. Mitul, divinul și cultele misterice au o puternică funcție educativă, în toate perioadele istorice.

Așa după cum afirma părintele Nicolae Achimescu, în lucrarea sa Istoria și filosofia religiilor la popoarele antice, se menține un conflict permanent între generațiile divine, în lupta lor pentru obținerea supremației universale. În acest sens, elocvente sunt episoadele sângeroase, de o duritate înfricoșătoare, dintre: Uranus și Haos, Cronos versus Uranus, Zeus împotriva lui Cronos. Cea mai savuroasă ascensiune la puterea lumilor o are Zeus, care se şi bucură de mai multe aventuri de un farmec literar cuceritor ${ }^{2}$.

În jurul divinităților și a marilor episoade de interacțiune dintre ei și oameni, au luat naștere cultele patronate de către zei. Dintre cele mai

2 Nicolae ACHIMESCU, Istoria şi filosofia religiei la popoarele antice, Iaşi, Edit. Tehnopress, 2000, p. 158. 
cunoscute astfel de culte, se remarcă: cel familial al vetrei casnice (patronat de puternica zeitate Demeter) și, îndeosebi, cultul eroilor. În prim plan erau eroii supradimensionați literar cu caracter simbolic, aidoma lui Hercule sau Prometeu. O altă categorie importantă era aceea a eroilor care s-au evidențiat ca vectori de acțiune, vârfuri de lance, în lumea noastră. Astfel, este vorba despre mari oameni politici, asemenea lui Lycurg, întemeietorul statului spartan, sau Chadmos, întemeietorul bogatului ținut al $\mathrm{Tebei}^{3}$. În aceeaşi categorie valorică pot fi incluşi artiștii, care au influențat și inspirat mase uriașe de oameni. Merită din plin menționați: artistul Dedal, iscusit meșter și inventator, artistul Pygmalion, cântăreții Orfeu, Arion și ilustrul Homer, autor al Bibliei grecilor antici, respectiv al epopeilor Iliada și Odiseea.

Inițial, cuvântul „erou” desemna pe cel plecat din lumea muritoare. Ulterior, forma sa denominativă a primit sensul de persoană extraordinară cu forță de motor și model pentru societate, deținând astfel și o mare putere educativă.

Trăsătura definitorie a mitului era puternica sugestivitate și înaltul valoric al conţinuturilor artistice care creau imagini cu un impact covârşitor și modelator asupra cititorului sau auditoriului. De altfel, mitologia și educația artistică s-au influențat permanent, cea de-a doua înnobilând mitologia prin umanizarea figurilor mitologice.

Zeii au impregnat o puternică amprentă educativă prin înalta ținută, standardele ridicate pe care le impuneau și prin care își măsurau puterea şi valoarea. Educaţia aristocratică s-a raportat permanent la aceste standarde, iar tipul respectiv de educație era preferat în statul antic grec ${ }^{4}$.

Pentru educația masculină, fizionomia socială a ales virilitatea îmbinată cu înţelepciunea. Întruchiparea cea mai fidelă a acestui tip de ideal pedagogic era eroul homeric, un cavaler prin excelență.

Pentru educația feminină, esențiala arete era frumusețea, acea frumusețe delicată care corespundea tipului cultural al manierelor distinse de la curțile nobiliare, ideal promovat de către toate epocile de cavalerism. Femeia, frumos educată, capabilă să-și manifeste feminitatea cu rafinament și eleganță, avea un efect călăuzitor și modelator într-o

${ }^{3}$ Ibidem, p. 195.

${ }^{4}$ Pierre HADOT, Ce este filosofia antică? , trad. George Bondor şi Claudiu Tipuriţă, Iaşi, Edit. Polirom, 1997, p. 39. 
societate brutală de războinici. Mai presus de utilitatea ei socială, respectiv maternitatea care îi era distinctă, femeia era adulată și respectată pentru faptul că existența ei înfrumuseța lumea, oferindu-i valoare, candoare și culoare, sens și motivație de a lupta și de a iubi ${ }^{5}$.

Alături de mituri, cultele misterice au avut o considerabilă funcție educativă nu numai prin arta inițiatică, ci și prin curentele pe care le-au lansat și coagulat, creând școli cu diferit specific ${ }^{6}$. Aceste culte misterice erau zămislite din obiceiuri primitive (ca și tradițiile populare de la noi) și se dezvoltau prin cultivarea „disciplinei tăcerii”, care avea rolul de a le proteja de profanare și certificau mântuirea în viața viitoare. Dețineau o finalitate optimistă, deoarece sufletul practicantului plecat străbătea împărăția lui Hades și putea trăi în grațiile și locașurile zeilor pentru totdeauna.

Treptele ritualice erau următoarele:

1. Spălarea neofitului, care avea în atenție atât curăţirea fizică, dar și pe cea sufletească. În acest sens, aspirantul avea de îndeplinit, în prealabil, câteva acțiuni prin care putea ilustra bunătatea și omenia, un fel de curățare a sufletului pentru a fi umplut cu virtuțile semnificative;

2. Însușirea preceptelor cultice însemna învățarea unui cod de reguli care îmbunătățeau viața aspirantului și îi asigurau o înţelegere a sensului vieții;

3. Participarea la actele sacre, cu invocarea formulelor de cult și aplicarea învățăturilor în viața de zi cu zi ${ }^{7}$.

Cultele misterice aveau finalitate garantată, în sensul că destinul victorios al zeului era transferat destinului plin de suferință al muritorului, conferindu-i acestuia fericirea nemuritoare ${ }^{8}$.

Se distingeau cultele grecești și cele orientale, deși se puteau sesiza și câteva interferențe sau note comune.

Dintre misterele grecești, cele mai răspândite și mai cunoscute sunt: misterele eleusine, misterele dionisiace, misterele orfice și misterele

${ }^{5}$ Petru COMĂRnESCU, Kalokagathon, Bucureşti, Edit. Eminescu, 1985, p. 322.

${ }^{6}$ Werner JAEger, Paideia. Vol. I, trad. Maria-Magdalena Anghelescu, București, Edit.

Teora, 2000, p. 37.

${ }^{7}$ Nicolae ACHIMESCU, Istoria şi filosofia religiei la popoarele antice, p. 187.

${ }^{8} \mathrm{~S}$. A. TOKAREV, Religia în istoria popoarelor lumii, trad. I. Vasilescu-Albu, Bucureşti, Edit. Politică, 1976, p. 195. 
pitagoreice. Cele ultime menționate au fost cel mai mult valorificate pedagogic. Pe de o parte, au generat o școală filosofică apreciată la acea vreme, dar în acelaşi timp formaseră și un partid politic influent (partidul aristocratic). A fost prima școală în sensul riguros al cuvântului, preluată ca model atât de Liceul lui Aristotel, cât și de Academia lui Platon sau de Școala lui Epicur. Școala pitagoreică a fost înființată de către Pitagora, matematician, om de știință erudit din insula Samos. Adepții acestei școli:

- erau vegetarieni;

- $\quad$ se închinau la Soare și Foc;

- credeau în reîncarnare;

- numărul era principiul primordial, generator a toate. Numărul 10 era numărul perfect; suma primelor patru numere dă cifra sacră. Numărul 5 era numărul familiei, al căsătoriei. Numerele 4 și 9 erau numerele justiţiei etc.;

- măsura sau stabilirea limitei era esențială în toate.

În secolul al V-lea, grecii antici realizează o inovație de mare răsunet și importanță pentru civilitate: polisul ${ }^{9}$. Omul este ființa a cărei mediu natural este cetatea și a cărei umanitate constă tocmai în calitatea sa de cetățean.

Apărea conceptul de OM, adică responsabilizarea lui. Setul de drepturi şi de îndatoriri îl responsabilizau oficial și plenar. Omul, ca cetățean, era vizat ca obiect și subiect al legii cetății, iar în morală și artă este sediu al valorilor tipice pe care le proclamă conștiința publică a cetății. Societatea se confundă cu politicul, ca normă a cetății.

Valorile tipice aveau nevoie de confirmarea religiei polisului. Totul, întregul ansamblu al vieții mundane, trebuia să preamărească valorile care contribuiau la consolidarea cetății și o menţineau la standarde înalte de cultură și moralitate. În acest sens, Platon condamna pe artiștii care alegeau ca teme situații conjuncturale supărătoare și tot ceea ce era ataşat trăirilor personale egocentriste, alterând sau prejudiciind valorile de prestigiu, clar jalonate, generalizate ${ }^{10}$.

Norma, mai ales în acea privință, avea nevoie de transpunere în practică din convingere, iar, la nevoie, din constrângere. Atât la Platon,

${ }^{9}$ Henri-Irénée Marrou, Istoria educatiei în antichitate. Vol. I, trad. Stella Petecel, Bucureşti, Edit. Meridiane, 1997, p. 25.

${ }^{10}$ ARISTOTEL, Etica nicomahică, trad. Stella Petecel, Bucureşti, Edit. IRI, 1998, p. 26. 
cât și la Aristotel, întâlnim pagini de înaltă expresie literară și morală cu privire la teme dedicate marilor valori, cum ar fi prietenia. Totul era dominat de idei și forme universalizante. Prototipul ideii este Socrate, principalul exponent literar platonician. Platon a fost partizan al metodelor active în școala sa.

În prima jumătate a secolului al V-lea din perioada clasică, încă mai era puternic patentul arhaic în educație. Idealul era cel aristocratic, iar modelul pentru educație era cel atenian. Acest model nu-și propunea formarea hoplitului, ca în statul spartan. De altfel, mult mai creativi, atenienii inventaseră efebia (serviciul militar specializat). Ca moștenire, funcționau turnirurile din perioada preclasică, dar și acestea fuseseră îmbunătățite prin tehnici de simulări sportive care generează „lupta inarmat".

Era preferat modelul aristocratic, iar privirea era ațintită asupra nobilului bine consolidat funciar, bogat și inactiv, încredințându-se mai puțină orientare către tipul real și activ al atenianului de mijloc. Acest tip de educație nobilă, superioară, aristocratică, s-a dorit foarte mult a fi generalizat. Învătăâântul livrat de către preceptorul personal sau erast nu mai făcea față. De aceea, s-a simțit nevoia înființării unui învățământ colectiv și astfel a apărut instituţia școliii ${ }^{11}$.

Învățământul se explică prin cultura în care se inițiază. Astfel, societatea ținea la clubul bărbaților și la conversația îmbinată cu oratoria. Banchetul sau masa care se organiza după petrecerea de seară era o adevărată evaluare a personalității celor prezenți. Convivii primeau rând pe rând ramura de mirt care le oferea dreptul la cântat, oportunitate de afirmare, de a etala ceea ce acumulau prin educație.

În secolul al VI-lea, apar școlile de medicină. Aproximativ în aceeași perioadă, educația primește privilegiul de a-și vedea unele rezultate, prin beneficiul oferit de existența unor specialiști și anume sofiștii, primii pedagogi de carieră. De la aceștia avem strategii didactice redutabile, cum ar fi: conferința, controversa academică, antilogia. Protagoras, Hippias, Isokrates, Gorgias, își educau discipolii să iasă învingători din orice împrejurare de comunicare și să facă față cu succes atunci când discută despre orice subiect în care considerau că este înțelept

${ }^{11}$ Ibidem, p. 27. 
să intervină. Maniera de a conduce comunicarea, elementele limbajului paraverbal, atitudinea studiată, toate indicau stăpânirea unei adevărate arte a comunicării.

Isokrates a rămas celebru pentru un cuvânt care elogia cunoașterea: „Considerăm greci nu pe cei prin a căror vene curge același sânge cu al nostru, ci pe cei care au ca preocupare cultura și înțelepciunea". Concomitent cu arta de a convinge, sofiștii au predat arta de a fi puternici în cuvânt: „cuvântul care învinge”.

Concomitent cu arta de a convinge, sofiştii predau o artă de a vorbi, iar acest aspect secund al pedagogiei lor nu este mai puţin important decât primul. La moderni, cuvântul vorbit a fost detronat de atotputernicia scrisului, ce se menţine şi în zilele noastre, în ciuda progreselor realizate de radio, televiziune, înregistrare. În Grecia Antică, şi mai ales în viaţa politică, dimpotrivă, cuvântul vorbit era rege.

Viaţa religioasă este instrumentul de măsură cel mai sensibil al cotiturii pe care o consemnăm în tumultul stărilor de spirit. Rolul de mare importanţă pe care îl joacă Homer în educaţia clasică ne face să determinăm cu precizie valorile acestei educaţii. Se poate vorbi despre ,un ev mediu homeric", pentru că structura politică şi socială a acelei societăţi arhaice prezintă analogii formale cu cea a Evului Mediu occidental.

Pe treapta cea mai înaltă se afla regele, împresurat de aristocraţia războinică, cuprinzând consiliul marilor vasali (oameni în vârstă, a căror experienţă îi făcea preţioşi şi care serveau drept instanţă judecătorească) şi ceata fidelilor (tineri războinici) care formează clasa nobilă. Oamenii simpli formau pedestrimea.

Astfel se prezintă tabloul care va explica trăsăturile originale ale tradiţiei educative în Grecia clasică. Cultura greacă s-a bucurat de eroii homerici, care erau nişte cavaleri. Tinerii dăruiesc suzeranului lor ceea ce poate fi numit un serviciu de curte; ca şi gentilomii din Evul Mediu, ei serveau la masă în timpul festinurilor regale (serviciul nobil, clar distinct de cel al simplilor servitori). Tot ei servesc la alcătuirea suitei: şapte tineri 1-au însoţit pe Ulise pentru a o duce pe Briseis lui Ahile. De asemenea, ei însoţesc pe preot la ceremoniile sacrificiale, deoarece ei cântă frumosul pean şi îl celebrează prin dansul lor pe Apărător ${ }^{12}$.

${ }^{12}$ Tudor Vianu, Studii de filosofie a culturii, Bucureşti, Edit. Eminescu, 1980, p. 356. 
Alături de ceremonii, jocurile constituie aspectul dominant al vieţii cavalerilor homerici. Viaţa nobilă era încă de atunci o viaţă de plăceri elegante: jocuri sportive, dans cu mingea, cântec al aedului, interpretare muzicală la liră, concursuri de elocinţă şi competiţii verbale. Mai existau jocurile funerare, cum ar fi cele în onoarea lui Patrokles: pugilatul, lupta, alergarea, înfruntarea călare cu lancea, aruncarea discului, tirul cu arcul, aruncarea suliţei şi sportul care va rămâne întotdeauna cel mai nobil, cel mai apreciat și anume: cursa de care.

Eroii lui Homer sunt de o politeţe deosebită, atât în lupta propriuzisă, cât şi în provocările verbale rituale ce preced încleştarea. Această atmosferă civilizată îşi găseşte desăvârşirea într-o mare delicateţe a atitudinii faţă de femeie, așa cum este ilustrat în respectul arătat Penelopei de către pretendenţi. Soţiile erau într-adevăr stăpânele casei, cele care conduceau conversaţia, în sensul monden al cuvântului.

A străluci, a fi învingător, a te afirma în competiţie, a săvârşi fapta de glorie care te va situa în faţa oamenilor, a celor vii şi, poate, în faţa posterităţii, în rândul întâi: pentru aceasta trăieşte şi pentru aceasta moare un om adevărat ${ }^{13}$. Fiinţa o etică a onoarei, care implica acceptarea orgoliului, departe de a fi fost un viciu şi însemna înalta dorinţă a acelui care aspiră la a deveni erou. Această idee înaltă despre glorie este cea care defineşte rolul propriu al poetului, rol de ordin educativ. Scopul operei sale nu este exclusiv de ordin estetic, ci constă şi în a imortaliza eroii. Platon afirmă că poetul ,încununează cu glorie nenumăratele fapte de seamă ale celor de demult şi astfel face educaţia posterităţii”.

Educaţia eroilor lui Homer se face prin intermediul mentorilor lor, mari exemple împrumutate de la tipuri legendare, exemple care trebuie să trezească în ei dorinţa de competiţie.

\section{Concluzie}

Secretul pedagogiei homerice este exemplul eroic. Aşa după cum sfârşitul Evului Mediu ne-a lăsat Imitaţia lui Iisus, Grecia clasică a transmis, prin Homer, Imitaţia eroului. Exemplul eroilor a impregnat sufletul grecilor ${ }^{14}$.

13 Platon, Opere, trad. Andrei Cornea, București, Edit. Ştiinţifică şi Enciclopedică, 1986, p. 36.

${ }^{14}$ Constantin Cucoş, Educaţia religioasă, Iaşi, Edit. Polirom, 1999, p. 135. 


\section{Referinţe bibliografice:}

1. ACHIMESCU, Nicolae, Istoria şi filosofia Religiei la popoarele antice, Iaşi, Edit. Tehnopress, 2000;

2. ARISTOTEL, Etica nicomahică, trad. Stella Petecel, Bucureşti, Edit. IRI, 1998;

3. COMĂRnescu, Petru, Kalokagathon, București, Edit. Eminescu, 1985;

4. CuCoş, Constantin, Educaţia religioasă, Iaşi, Edit. Polirom, 1999;

5. HADOT, Pierre, Ce este filosofia antică?, trad. George Bondor şi Claudiu Tipuriță, Iași, Edit. Polirom, 1997;

6. MARrou, Henri-Irénée, Istoria educatiei în antichitate. Vol. I, trad. Stella Petecel, Bucureşti, Edit. Meridiane, 1997;

7. JAeger, Werner, Paideia. Vol. I, trad. Maria-Magdalena Anghelescu, București, Edit. Teora, 2000;

8. Platon, Opere, trad. Andrei Cornea, București, Edit. Ştiinţifică şi Enciclopedică, 1986;

9. TOKAREV, S. A., Religia în istoria popoarelor lumii, trad. I. VasilescuAlbu, Bucureşti, Edit. Politică, 1976;

10. VIANU, Tudor, Studii de filosofie a culturii, Bucureşti, Edit. Eminescu, 1980. 